\title{
Sepsis-induced acute kidney injury in oral and maxillofacial infection with upper airway obstruction due to retropharyngeal abscess: a case report
}

\author{
Irsan Kurniawan, ${ }^{1 *}$ Agus Nurwiadh, ${ }^{1}$ Kiki Lukman ${ }^{2}$
}

\begin{abstract}
Objective: Left untreated or not properly managed odontogenic infection can cause spreading into facial spaces. Severe oral and maxillofacial infection can spread systemically and cause sepsis. Sepsis can induce unfavorable condition for the kidney, which is Acute Kidney Injury (AKI). The aim of this paper is to report a rare case of an oral and maxillofacial infection with sepsis-induced AKI and upper airway obstruction which have high mortality rate.

Methods: A 48-year-old female patient with oral and maxillofacial infection suffers sepsis-induced AKI and upper airway obstruction was diagnosed as right submandibular abscess which has extended into right buccal space, with sepsis, stage I AKI and upper airway

obstruction due to retropharyngeal abscess. We managed this patient with oxygenation, fluid resuscitation, antibiotics and analgesic administration, incision and drainage, also extraction of mandibular right third molar.

Results: Tracheostomy, incision and drainage of retropharyngeal abscess were supposed to be performed by ENT department, but the patient refused. However the patient still survived.

Conclusion: In case of oral and maxillofacial infection, the involvement of distant organ should be investigated, because this conditions result in high mortality rate. Early diagnosis and prompt treatment are important and able to lead to a better survival.
\end{abstract}

'Department of Oral and Maxillofacial Surgery, Hasan Sadikin General Hospital, Bandung, Indonesia

${ }^{2}$ Department of Digestive Surgery, Hasan Sadikin General Hospital, Bandung, Indonesia
*Correspondence to: Irsan Kurniawan, Department of Oral and Maxillofacial Surgery, Hasan Sadikin General Hospital irsankurniawan82@gmail.com

Received: 040 0ctober 2016 Revised: 15 November 2016 Accepted: 22 November 2016 Available Online: 18 December 2016

Keywords: Acute kidney injury, Sepsis, Tracheostomy

Cite This Article: Kurniawan I, Nurwiadh A, Lukman K. 2016. Sepsis-induced acute kidney injury in oral and maxillofacial infection with upper airway obstruction due to retropharyngeal abscess a case report. Journal of Dentomaxillofacial Science 1(3): 201-205. D0I:10.15562/jdmfs.v1i3.318

\section{Introduction}

Infection from submandibular abscess due to mandibular third molar infection can spread into retropharyngeal space through the lateral pharyngeal space which is close by. ${ }^{1}$ Sepsis can induce unfavorable condition for the kidney, which is Acute Kidney Injury (AKI)., ${ }^{2,3}$ When the retropharyngeal or prevertebral fascial spaces or both are involved as a result of odontogenic infection, the patient mostly gets serious ill. The followings are the three greatest potential complications: the serious possibility of upper airway obstruction as a result of anterior displacement of the posterior pharyngeal wall into the oral pharynx; rupture of the retropharyngeal abscess, with aspiration of pus into the lungs and subsequent asphyxiation; and spread of the infection from the retropharyngeal spaces into the mediastinum, which results in severe infection in the thorax. ${ }^{1,4-6}$

When a patient has extension of infection into the cervical region, the retropharyngeal space must be evaluated with lateral radiographs of the neck to determine whether the space is enlarged and thereby compromising the airway, causing upper airway obstruction. ${ }^{1,4,5}$
Fortunately, clinically significant sepsis is rarely caused by infections in the maxillofacial region for several reasons, however mostly sepsis can be resulted from any untreated infection of the head and neck and can occur in immunodeficient patients with maxillofacial infections. The most severe manifestation of sepsis is diffuse peripheral vasodilation, which produces septic shock. The vasodilation that occurs during sepsis is believed to be caused by toxins produced by infecting organisms and release of vasoactive substances as the result of the interaction between bacterial products and infected tissues, white blood cells and platelets. ${ }^{1}$ The peripheral vasodilation produces a relative hypovolemia, impairing perfusion of vital organs, such as kidney. Hypoperfusion due to peripheral vasodilation may lead to $\mathrm{AKI}$, this is the most common form of prerenal AKI. Pre-renal AKI is generally reversible when renal perfusion pressure is restored. However, more severe or prolonged hypoperfusion may lead to ischemic injury, often termed Acute Tubular Necrosis (ATN). ${ }^{2}$

As mentioned above, the infections of oral and maxillofacial originated from odontogenic 
infection rarely cause sepsis and inducing AKI, but in this case report we present an oral and maxillofacial infections with sepsis-induced AKI which has high mortality rate. Early diagnosis and prompt management lead to patient's survival.

AKI is defined as any of the following conditions (not graded), increase in SCr by $\geq 0.3 \mathrm{mg} / \mathrm{dl}$ ( $\geq$ $26.5 \mu \mathrm{mol} / \mathrm{l}$ ) within 48 hours; or increase in Scr to $\geq 1.5$ times baseline, which is known or presumed to have occured within the prior 7 days; or urine output $<0.5 \mathrm{ml} / \mathrm{kg} / \mathrm{h}$ for 6 hours. The Etiology of AKI include pre-renal, intrinsic renal and post-renal. Sepsis can induce pre-renal AKI following renal hypoperfusion. ${ }^{7-9}$

AKI commonly happens with hospitalized patients and also has a poor prognosis with the mortality ranging from $10 \%-80 \%$ dependent upon the patient population studied. Patients who present with uncomplicated AKI, have a mortality rate of up to $10 \%$. In contrast, patients presenting with AKI and multiorgan failure have been reported to have mortality rates over $50 \%$. If renal replacement therapy is required, the mortality rate rises further to as high as $80 \% .^{9}$
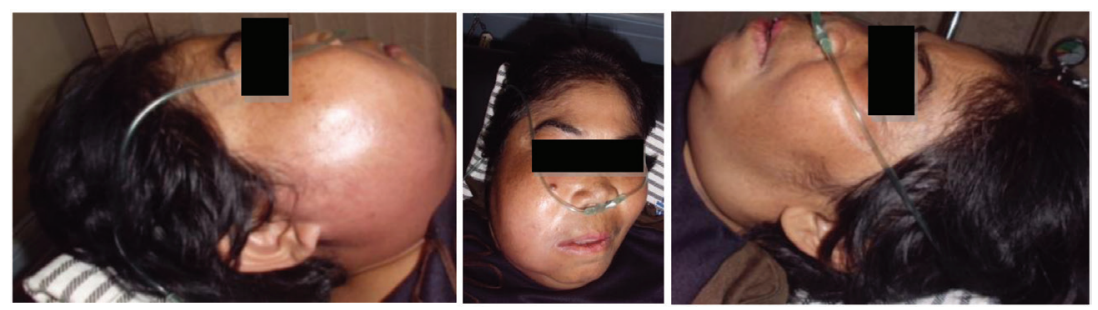

Figure 1 Clinical appearance patient with right submandible abscess which spreads into right buccal space

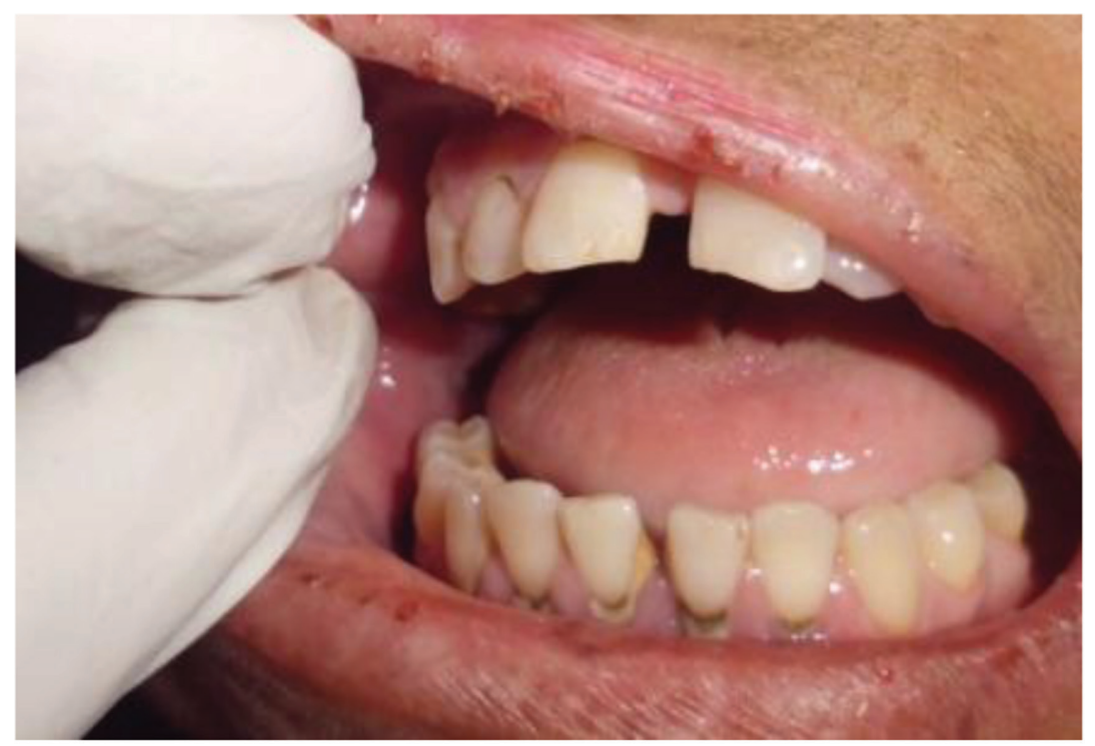

Figure 2 Intraoral photograph of this patient, also showing dry labial mucosa

\section{Case Report}

A 48 year old female patient was admitted to Hasan Sadikin Hospital referred from local hospital for oral and maxillofacial infection. She complained about pain and swelling on her right cheek since four days prior to admission. About seven days before admitted to hospital, patient complained about pain on her right most posterior mandibular tooth accompanied with fever and then she seek for help to local dentist and was given four kinds of medicine. After taking the medicine for several days, the patient found no improvement and her right cheek swelled that the patient went to local hospital and then referred to Hasan Sadikin General Hospital.

In our physical examination we found an increase in pulse rate of 102 beats/min, body temperature of $38.6^{\circ} \mathrm{C}$, respiratory rate of 24 breaths $/ \mathrm{min}$. A slight decrease in skin turgor and inspiratory stridor were also revealed. Her conjunctiva was anemic. Neck examination revealed that the right submandible lymph node was difficult to assess due to swelling on her right submandible, other physical examinations were within normal limit. In extraoral examination we found facial asymetry due to diffused, fluctuative and hyperemic swelling on her right submandible which is spreading into right buccal, accompanied with pain on pressure. Local temperature was warm on this swelling figure 1 .

Patient's mouth opening was about $1.5 \mathrm{~cm}$. Intraoral examination revealed spontaneous pus drainage at mandibular right third molar region and profound caries within this tooth, plaque and calculus were also found around this tooth and neighbouring teeth, we also found dry labial mucosa figure 2.

This patient was diagnosed as right submandibular abscess which has spreaded into right buccal space, with sepsis, stage I AKI and upper airway obstruction due to retropharyngeal abscess. AKI staging based on criteria proposed by AKI Network table 1.

We managed this patient with oxygenation via nasal canule $3 \mathrm{~L} / \mathrm{mnt}$, fluid resuscitation with moderate rehydration by 132 drops/mnt of crystalloid for the first 6 hours followed by urinary catheter insertion for monitoring urine output, pus aspirations, administration of $1 \mathrm{gr}$ of ceftriaxone, $500 \mathrm{mg}$ of metronidazole, $50 \mathrm{mg}$ of ranitidine, 30 mg of ketorolac intravenously and laboratory examination including culture, resistence and sensitivity test, radiograph examination, consultation to ENT and internal medicine department. The interpretation of AP and lateral neck soft tissue radiographs showed narrowing of laryngeal and pharyngeal airway column, widening of retropharyngeal and 


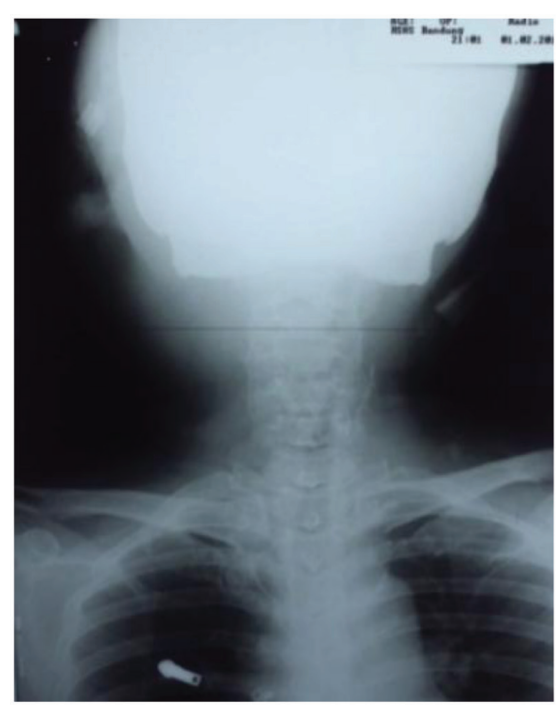

A

Figure 3 Patient's antero-posterior A. Lateral, B. Neck soft tissue radiograph
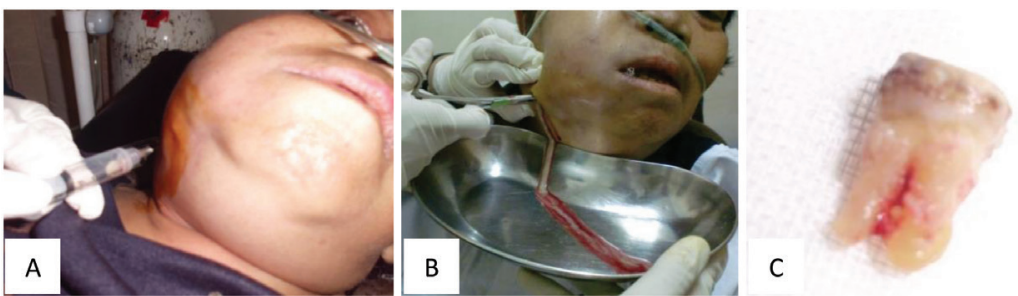

Figure 4 A. Pus aspiration for bacterial culture resistention and sensitivity, B. Incision and drainage, $\mathrm{C}$. Tooth extraction

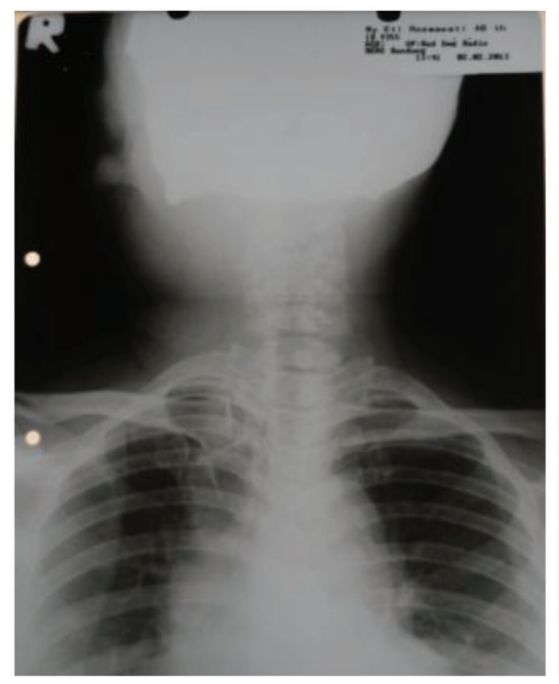

A

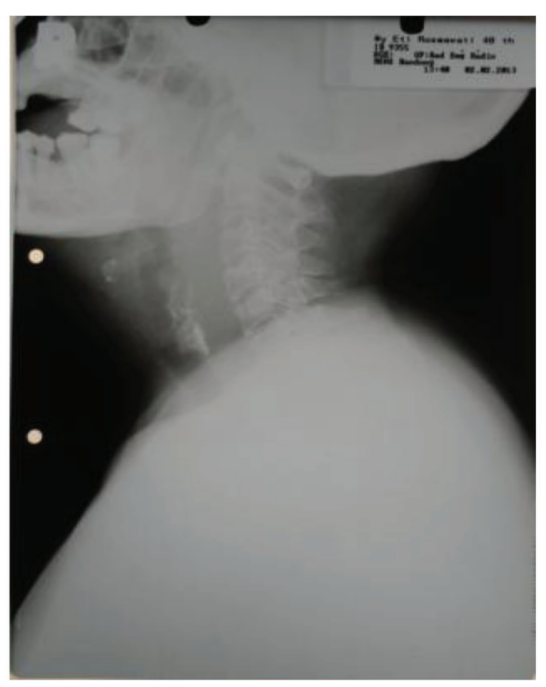

B
Figure 5 A. Patient's antero-posterior radiographs, B. Lateral neck soft tissue radiographs 1st day after surgery revealed laryngeal and pharyngeal airway column within normal limit

retrolaryngeal spaces, also an appearance of opaque shadow with soft tissue density at the right side of the neck with calcification. These neck soft tissue radiographs gave images for a soft tissue mass at right neck figure 3 .

Laboratory findings revealed moderate anemia, leukocytosis, thrombocytosis, metabolic acidosis, decreased oxygen saturation, also increase in ureum and creatinin serum.

We performed surgical intervention for the maxillofacial abscess consisted of extraoral incision and drainage as well as extraction of the mandibular right third molar, we found pus about $50 \mathrm{cc}$ figure 4. Tracheostomy, incision and drainage of retropharyngeal abscess supposed to be performed by ENT department, but the patient refused.

For inpatient care we managed this patient with fluid resuscitation and administration of ceftriaxone $2 \times 1$ gr, metronidazole $3 \times 500 \mathrm{mg}$, ranitidine $2 \times 50 \mathrm{mg}$, and antrain $3 \times 500 \mathrm{mg}$ intravenously, also nutritional support with soft diet $1800 \mathrm{Kcal} /$ day, protein $1 \mathrm{gram} / \mathrm{Kg} /$ day, carbohydrate: fat ratio = 70:30\%. We also monitored vital signs, any signs of worsening upper airway obstruction, the patient's urine output, her ureum and creatinine serum level by serial laboratory examination and also pus production. ENT department planned to perform tracheostomy and incision drainage for retropharyngeal abscess, but the patient still refused.

On the first day after surgery, we performed neck soft tissue radiographs re-examination to reevaluate airway column and the extent of retropharyngeal abscess. Compared with the results of previous emergency radiographs examination, this radiographs revealed laryngeal and pharyngeal airway column within normal limit, widening of retropharyngeal and retrolaryngeal space at C1-4 level figure 5. Clinically there was no any sign of worsening upper airway obstruction, there was no inspiratory stridor, respiratory rate was $17 \mathrm{x} / \mathrm{mnt}$. We did fluid resuscitation for next 18 hours as much as 65 drops/minutes of crystalloids, we also replaced the analgesic to antrain $3 \times 500 \mathrm{mg}$ intravenously as consideration of the patient's kidney.

We found improvement in AKI condition for this patient, which is decrease in serum creatinine as well as increase in urine output since we did fluid resuscitation and nutritional support for this patient following the incision and drainage that had previously been done and tooth extraction as source control.

On the fifth day after incision, drainage, and tooth extraction patient asked to return home without consent. Patient went home with improvement in her AKI condition with SCr $0.73 \mathrm{mg} / \mathrm{dL}$ and urine output $>0.5 / \mathrm{kg} / \mathrm{h}$ for $6-12$ hours table 2 , the infections and sepsis condition also subsides. We also suggested her to come to Oral and Maxillofacial Surgery out patient clinic for follow up and control at Hasan Sadikin Hospital. 
Table 1 Criteria for AKI staging according AKIN

\begin{tabular}{|c|c|c|}
\hline Stage & Serum creatinine & Urine output \\
\hline 1 & $\begin{array}{l}1.5-1.9 \text { times baseline or } \geq 0.3 \mathrm{mg} / \mathrm{dl}(\geq 26.5 \\
\mu \mathrm{mol} / \mathrm{l}) \text { increase }\end{array}$ & $\begin{array}{l}<0.5 \mathrm{ml} / \mathrm{kg} / \mathrm{h} \text { for } 6-12 \\
\text { hours }\end{array}$ \\
\hline 2 & $2.0-2.9$ times baseline & $\begin{array}{l}<0.5 \mathrm{ml} / \mathrm{kg} / \mathrm{h} \text { for } \geq 12 \\
\text { hours }\end{array}$ \\
\hline 3 & $\begin{array}{l}3.0 \text { times baseline or Increase in serum } \\
\text { creatinine to } \geq 4.0 \mathrm{mg} / \mathrm{dl}(\geq 353.6 \mu \mathrm{mol} / \mathrm{l}) \text { or } \\
\text { Initiation of renal replacement therapy or in } \\
\text { patients }<18 \text { years, decrease in eGFR to }<35\end{array}$ & $\begin{array}{l}0.3 \mathrm{ml} / \mathrm{kg} / \mathrm{h} \text { for } \geq 24 \\
\text { hours } \\
\text { or } \\
\text { Anuria for } \geq 12 \text { hours }\end{array}$ \\
\hline
\end{tabular}

Table 2 Improvement in AKI condition

\begin{tabular}{lccccc}
\hline Date & $\mathbf{0 1 / 0 2 / 2 0 1 3}$ & $\mathbf{0 1 / 0 2 / 2 0 1 3}$ & $\mathbf{0 3 / 0 2 / 2 0 1 3}$ & $\mathbf{0 5 / 0 2 / 2 0 1 3}$ & $\begin{array}{c}\text { Reference } \\
\text { value }\end{array}$ \\
\hline $\mathrm{SCr}(\mathrm{mg} / \mathrm{dL})$ & 1.46 & 1.49 & 1.21 & 0.73 & $0.5-0.9$ \\
$\mathrm{UO} / 12 \mathrm{jam}$ & Initial:50 cc & $30 \mathrm{cc} / \mathrm{hours}$ & $250 \mathrm{cc}$ & $550 \mathrm{cc}$ & $360 \mathrm{cc}$ \\
\hline
\end{tabular}

\section{Discussion}

Left untreated or not properly managed odontogenic infection can cause spreading into facial spaces. In this case, facial spaces infection were caused by mandibular right third molar infection. Spread of infection started through right submandibular abscess which then spreaded into right buccal space. Besides that, submandibular abscess originated from mandibular third molar infection can spreads contiguously into pharyngeal lateral space medially. Anatomically, lateral pharyngeal space have close approximation to retropharyngeal space, hence infection from lateral pharyngeal space can spreads into retropharyngeal space resulting in retropharyngeal abscess. ${ }^{1}$

If this retropharyngeal infection is not treated immediately, it can potentially result in upper airway obstruction because of anterior displacement of posterior wall of pharynx, rupture of the abscess and aspiration of the pus into the lung resulting in asphyxiation, also can cause mediastinitis. ${ }^{1,4,5}$

Grade I upper airway obstruction diagnosis due to retropharyngeal abscess was established through clinical examination as having inspiratory stridor accompanied by mild suprasternal retraction without infraclavicle, epigastric and intercostal retraction. Upper airway obstruction grading was based on Jackson's classification. We performed AP and lateral neck soft tissue radiographs, revealed narrowing in airway column and widening in retropharyngeal space. This space was measured at $\mathrm{C} 2$ level, normally the retropharyngeal width at C2 level is $6 \mathrm{~mm}$, whereas retrotracheal space measured at C6 level towards posterior pharynx soft tissue is not more than $20 \mathrm{~mm} .^{1}$
This patient supposed to be performed tracheostomy under local anesthesia and incison drainage for retropharyngeal abscess under general anesthesia. Unfortunately, patient refused tracheostomy and incision drainage by ENT department, but she still survived. We did close observation in vital signs and any sign in worsening upper airway obstruction for five days, and there was no signs of worsening in upper airway obstruction. Through early diagnosis and antibiotic therapy, some reports indicate that $10 \%$ to $40 \%$ of retropharyngeal infections resolve with only medical management. ${ }^{1}$

This patient also presented sepsis with blood pressure of 100/60 $\mathrm{mmHg}$, pulse rate of 102 beats/ min, body temperature of $38.6^{\circ} \mathrm{C}$ and respiration rate of 24 breaths/min due to oral and maxillofacial infection with WBC count of $25.600 / \mathrm{mm} 3$. However, the most severe manifestation of sepsis is diffuse peripheral vasodilation, which produces septic shock. The vasodilation that occurs during sepsis is believed to be caused by toxins produced by infecting organisms and release of vasoactive substances as the result of the interaction between bacterial products and infected tissues, white blood cells, and platelets. The peripheral vasodilation produces a relative hypovolemia, impairing perfusion of vital organs, such as kidney. ${ }^{1,2,7}$

Sepsis-induced AKI is defined by the simultaneous presence both of the RIFLE/ AKIN criteria for AKI and the consensus criteria for sepsis and by the absence of other clear and established, non-sepsis related causes of AKI. ${ }^{3,10}$ Its mortality varies with the severity of AKI from $20.9 \%$ to $56.8 \%$. The obvious conclusion is that septic AKI is a major problem in ICU patients that requires investigation and a clearer understanding of its pathogenesis. ${ }^{3,10}$ This patient was diagnosed as having stage I AKI according to serum creatinin level $1.46 \mathrm{mg} / \mathrm{dL}$ as well as decreased urine output within six hours. This is a rare and unique case of oral and maxillofacial infections derived from odontogenic infection with kidney involvement. Although this is a rare case we must always be aware of this condition and do not neglect it, and not only focused on the oral and maxillofacial region itself.

\section{Conclusion}

In case of oral and maxillofacial infection, the involvement of distant organ should be investigated, because this conditions result in high mortality rate, early diagnosis and prompt treatment are important and lead to better survival. 


\section{Conflict of Interest}

The authors report no conflict of interest.

\section{References}

1. Topazian RG, Goldberg MH, Hupp JR. Oral and maxillofacial infection. 4th ed. Philadelphia: WB Saunders Company; 2002.

2. Fauci AS, Kasper DL, Longo DL, et al. Harrison's principles of internal medicine. 17th ed. USA: McGraw-Hill; 2008.

3. Wan L, Bagshaw SM, Langenberg C, et al. Pathophysiology of septic acute kidney injury: what do we really know? Crit Care Med 2008;36.

4. Peterson LJ, Ellis E, Hupp JR, et al. Contemporary oral and maxillofacial surgery. 4th ed. St.Louis: Missouri Mosby; 2003.

5. Fragiskos FD. Oral surgery. Berlin: Springer; 2007.

6. Balaji SM. Textbook of oral and maxillofacial surgery. New Delhi: Elsevier; 2009.
7. Sudoyo AW, Setiyohadi B, Alwi I, et al. Buku ajar ilmu penyakit dalam. 5th ed. Jakarta: Interna Publishing; 2009.

8. Kellum JA. Clinical Practice Guideline for Acute Kidney Injury. KDIGO 2012;2.

9. Lewington A, Kanagasundaram S. Clinical practice guidelines. 5th ed. UK Renal Association; 2011.

10. Regueiraa T, Andresena M, Mercadoa M, et al. Review physiopathology of acute renal failure during sepsis. Med Intensiva elsevier España 2011;35: 424-432.

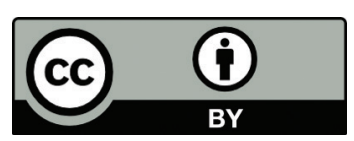

This work is licensed under a Creative Commons Attribution 